\title{
THE COSMIC DYNAMO
}

Edited by F. KRAUSE, K.-H. RÄDLER and G. RÜDIGER
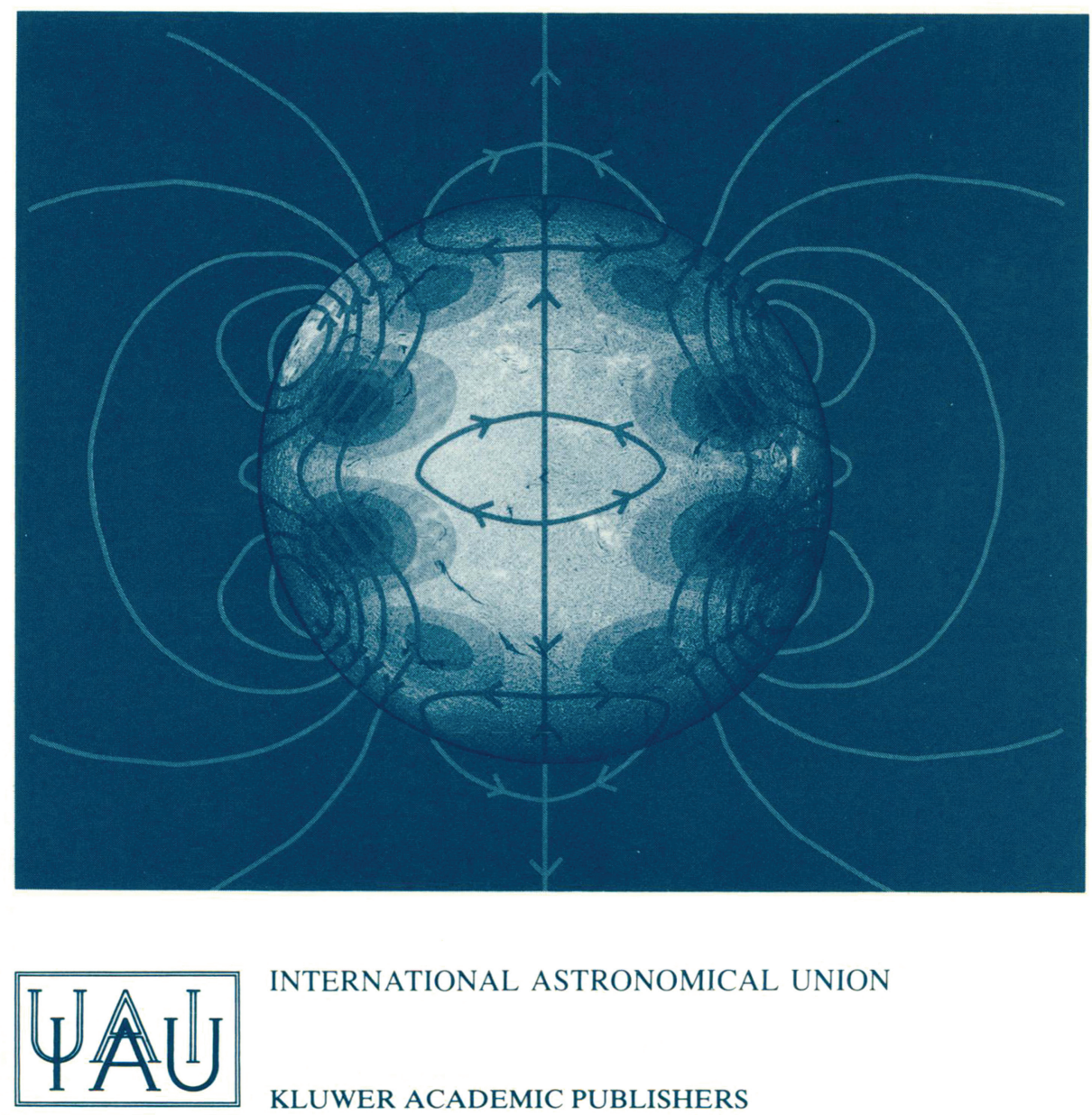

INTERNATIONAL ASTRONOMICAL UNION

KLUWER ACADEMIC PUBLISHERS 
THE COSMIC DYNAMO 


\title{
THE COSMIC DYNAMO
}

PROCEEDINGS OF THE 157TH SYMPOSIUM OF THE INTERNATIONAL ASTRONOMICAL UNION,

HELD IN POTSDAM, GERMANY, SEPTEMBER 7-11, 1992

\author{
EDITED BY \\ F. KRAUSE \\ K.-H. RÄDLER \\ and \\ G. RÜDIGER \\ Astrophysikalisches Institut, \\ Potsdam, Germany
}

\section{KLUWER ACADEMIC PUBLISHERS}

DORDRECHT / BOSTON / LONDON

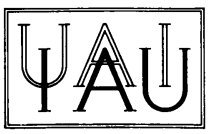


Library of Congress Cataloging-in-Publication Data

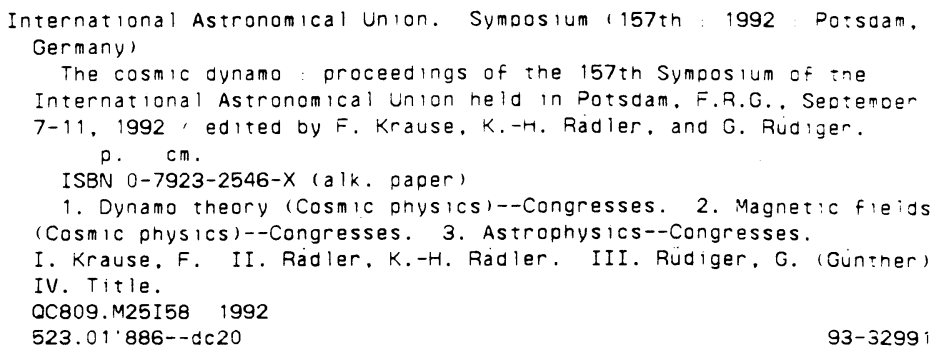

\title{
Published on behalf of \\ the International Astronomical Union
}

by

Kluwer Academic Publishers, P.O. Box 17, 3300 AA Dordrecht, The Netherlands.

Kluwer Academic Publishers incorporates the publishing programmes of D. Reidel, Martinus Nijhoff, DrW. Junk and MTP Press.

Sold and distributed in the U.S.A. and Canada

by Kluwer Academic Publishers, 101 Philip Drive, Norwell, MA 02061, U.S.A.

In all other countries, sold and distributed by Kluwer Academic Publishers Group, P.O. Box 322, 3300 AH Dordrecht, The Netherlands.

\section{Printed on acid-free paper}

\author{
All Rights Reserved \\ @ 1993 International Astronomical Union
}

No part of the material protected by this copyright notice may be reproduced or utilized in any form or by any means, electronic or mechanical including photocopying, recording or by any information storage and retrieval system, without written permission from the publisher.

Printed in the Netherlands 


\section{TABLE OF CONTENTS}

Preface xiii

List of Participants $\quad$ Xv

$\begin{array}{ll}\text { List of Contributors } & \text { XXV }\end{array}$

\section{The Solar Dynamo}

The Solar Dynamo

D. SCHMITT

Turbulent Transport of Magnetic Fields and the Solar Dynamo

L.L. KICHATINOV

Existence and Energy Balance of the Solar Dynamo

J.H.G.M. VAN GEFFEN

Complete Alpha-Tensor for Solar Dynamo

V.N. KRIVODUBSKIJ and M. SCHULTZ

Flux Tubes and Dynamos

M. SCHÜSSLER

Storage of Magnetic Flux in the Overshoot Region

F. MORENO-INSERTIS, M. SCHÜSSLER and A. FERRIZ-MAS

On the Stability of Magnetic Flux Tubes in the Equator of a Star

A. FERRIZ-MAS and M. SCHÜSSLER

Non-Linear Diamagnetic Transport of the Large-Scale Magnetic Field in the Solar Convection Zone

V.N. KRIVODUBSKIJ

MHD Turbulence in the Solar Wind and Interplanetary Dynamo Effects

E. MARSCH and C.-Y. TU

Solar Coronal Magnetic Fields

J. HILDEBRANDT, B. KLIEM and A. KRÜGER 


\section{Long-Term Variability of the Solar Magnetic Cycle}

Nonlinear Coupling Between the 110-year Periodic Modulations of Solar Differential Rotation and Solar Cycle

H. YOSHIMURA

Can Mean Helicity Fluctuations Explain the Variability of the Solar Cycle?

P. HOYNG

Magnetic Field and Differential Rotation of the Sun

W. KUNDT

Chaos in Nonlinear Dynamo Models

J. KURTHS, A. BRANDENBURG, U. FEUDEL and W. JANSEN

On the Dimension of the Solar Activity Attractor

C.-M. ORZARU

Dipole Field, Sunspot Cycle and Solar Dynamo

P.A. SIMON and J.P. LEGRAND

On the Fluctuations of the Total Solar Irradiance

W. SCHRÖDER and H.J. TREDER

Solar and Auroral Activities During the 17th Century

J.P. LEGRAND, M. LE GOFF, C. MAZAUDIER and W. SCHRÖDER

\section{Numerical Simulations of Convection and Dynamo Processes}

Simulating the Solar Dynamo

A. BRANDENBURG

Reynolds Stresses Derived from Simulations

P. PULKKINEN, I. TUOMINEN, A. BRANDENBURG and

A. NORDLUND

A Numerical Approach to Dynamically Consistent Spherical Dynamo Models

H. FUCHS, K.-H. RÄDLER and M. SCHÜLER

Asymptotic Model for Large-Scale Quasiheliostrophic Flow

M. GHIZARU 


\section{Late-Type and Other Stars}

Rossby Number or Rotation Period?

K. STȨPIEŃ

Alpha-Quenched Alpha-Lambda Dynamos and the Excitation of Nonaxisymmetric Magnetic Fields

D.M. BARKER and D. MOSS

Magnetic Braking of Late-Type Stars

L. MESTEL

Long-Term Spot Photometry and Differential Rotation of the Spotted Flare Stars EV Lac and BY Dra

K.P. PANOV

Emission Regions on the Flare Star EV Lac IN 1989

L.A. PUSTIL'NIK, I.P. PANFEROVA, R.E. GERSHBERG

and N.I. SHAKHOVSKAYA

The HeI $\lambda 10830 \AA$ Observations of Two RS CVn Systems $\zeta$ and $\lambda$ And

A.G. SHCHERBAKOV, M.J. FERNANDEZ-FIGUEROA,

F. MARTIN-PARRA, E. DE CASTRO and M. CORNIDE

Dynamo and Fossil Magnetic Field in Young Stars

A.E. DUDOROV

Enhancement of Magnetic Fields in High-Gravity Stars due to an Intrinsic Dynamo Effect

D. ENGELHARDT and I. BUES

Bipolar Flows During Early and Late Phases of Star Evolution

K. VOLKAMER and C. STREICHER

\section{Magnetic Field Generation in Accretion Disks}

Dynamo-Action in Accretion Disks

W. DEINZER

Magnetic Fields in Thin Accretion Disks Around Black Holes

R. KHANNA and M. CAMENZIND 
viii

Generation of Magnetic Fields in Accreting Systems as a Basis of Nonthermal Mode of Energy Release

$$
\text { L.A. PUSTIL'NIK and N.R. IKHSANOV }
$$

Kinematic Dynamo in Turbulent Circumstellar Disks

T. STEPINSKI

Dynamo Action in Accretion Disks

U. TORKELSSON

The Internal Wave Driven Dynamo in Accretion Disks

E.T. VISHNIAC

Accretion Disk Flares in Energetic Radiation Fields

R.F. VAN OSS, G.H.J. VAN DEN OORD and M. KUPERUS

\section{General Aspects of Dynamo Theory}

Bifurcations and Symmetry-Breaking in Simple Models of Nonlinear Dynamos N.O. WEISS

The Magnetic Field Structures of a Class of Fast Dynamos

Y.-T. LAU and J.M. FINN

Stationary Turbulent Dynamo as Spontaneous Symmetry Breaking

M. HNATICH

On the Gyrotropic Magnetohydrodynamic Turbulence

M. HNATICH and M. STEHLIK

The Non-linear Equations for the Green Function and Calculation of the Magnetic

Field Turbulent Diffusivities and $\alpha$-Effect

N.A. SILANT'EV

Dynamo Driven by Weak Plasma Turbulence

Y. TONG and A.C.-L. CHIAN

An Improved Reynolds Technique for Approximate Solution of Linear Stochastic Differential Equations

J. STAHLBERG

Calculation of the Electrical Conductivity of Plasmas with Fluctuations of the Electromagnetic Field

C.-V. MEISTER 
Inverse Energy Cascade in Advanced MHD Turbulence (the RNG Method)

N. KLEEORIN and I. ROGACHEVSKII

Non-Axisymmetric Magnetic Structure Generation in Planets Sun and Galaxies S.V. STARCHENKO

A Torsion-Induced Coupling Between Electric and Magnetic Fields in the Solar Convection Zone

M. SANIGA

\section{Magnetic Fields in Galaxies: Observations}

Radio Astronomy Techniques of Observing Magnetic Fields: The Galaxy

R. WIELEBINSKI

The Local Magnetic Field in our Galaxy

J.-L. HAN and G.-J. QIAO

Galactic Dynamos - a Challenge for Observers

R. BECK

The Intrinsic Magnetic Field Orientation in NGC 4631: Dynamo or Outflow?

G. GOLLA and E. HUMMEL

High Resolution Observations of the Magnetic Field in IC 342

M. KRAUSE

Magnetic Fields in the Spiral Galaxy NGC 6946

M. EHLE and R. BECK

The Magnetic Field of M 51

N. NEININGER, C. HORELLOU, R. BECK, E.M. BERKHUIJSEN,

M. KRAUSE and U. KLEIN

The Magnetic Field of M 83

N. NEININGER, U. KLEIN, R. BECK and R. WIELEBINSKI

Magnetic Fields in the Irregular Galaxy LMC

R. WIELEBINSKI 


\section{Magnetic Fields in Galaxies: Dynamo Theory}

The Galactic Dynamo: Modes and Models

G. RÜDIGER, D. ELSTNER and M. SCHULTZ

Galactic Dynamos and Dynamics

K.J. DONNER, A. BRANDENBURG and M. THOMASSON

Towards the Magnetic Field of M 81

D. MOSS, A. BRANDENBURG, K.J. DONNER and M. THOMASSON

Numerical Models of 3-D Galactic Dynamos

J.S. PANESAR, N. MOORE and A.H. NELSON

Nonlinear Dynamo in a Disk Galaxy

A. POEZD, A. SHUKUROV and D.D. SOKOLOFF

Boundary Layer in Nonlinear Dynamo

K.M. KUZANYAN and L. KVASZ

Magnetic Field Generation by Galactic Winds

S.J. SPENCER and L.E. CRAM

Hydromagnetic Dynamo in Astrophysical Jets

A.M. SHUKUROV and D.D. SOKOLOFF

Nonlinear Interaction between Magnetic Fields and Spiral Arms

M. CHIBA

Basic Properties of Swing-Excitation Mechanism

M. CHIBA and M. HANASZ

On the Parametric Resonance in Thin Disk Galactic Dynamo

K.M. KUZANYAN and D.D. SOKOLOFF

\section{Magnetohydrodynamic Phenomena in the Interstellar Medium Related to Dynamo Processes}

The Full "Alpha-Tensor" due to Supernovae and Superbubbles in the Galactic Disk K.M. FERRIÈRE

The Alpha-Effect by Supernova Explosions

M. KAISIG; G. RÜDIGER and H.W. YORKE 
Galactic Dynamics and Magnetic Field Amplification

H. LESCH

Parker Instability and the Galactic Dynamo

M. HANASZ and H. LESCH

3D-Numerical Simulations of Magnetic Field Evolution in the Turbulent Interstellar Gas

K. OTMIANOWSKA-MAZUR and M. URBANIK

Observational Properties of Helical Magnetic Fields

M. URBANIK and K. OTMIANOWSKA-MAZUR

On the Predictive Power of the Minimum Energy Condition

M. POHL

Dynamical Galactic Halos

D. BREITSCHWERDT, H.J. VÖLK, V. PTUSKIN

and V. ZIRAKASHVILI

Generation of the Seed Magnetic Field

A. LAZARIAN

Statistical Method for Astrophysical Turbulence Investigation

A. LAZARIAN

Magnetic Field Generation within Molecular Clouds

A. LAZARIAN

429

10. Geodynamo and Planetary Dynamos

The Geodynamo

P.H. ROBERTS

A New Numerical Scheme in the Solution of the Geodynamo Z-Model

P. HEJDA and A.P. ANUFRIJEV

Time Evolution of the Solution in Model Z

A.P. ANUFRIEV, I. CUPAL and P. HEJDA

Ekman-Hartmann Boundary Layers and the Length of Day Variations

N. KLEEORIN, I. ROGACHEVSKII and A. RUZMAIKIN 
xii

Mean Electromotive Force due to Magnetoconvection in Rotating Horizontal Layer in Dependence on Boundary Conditions

J. BRESTENSKÝ, S. ŠEVČIK and L. ROSENBERG

The Solar Dynamo and Planetary Dynamo

H. YOSHIMURA

Nonlinear Dynamo of Magnetic Fluctuations and Flux Tubes Formation in the Ionosphere of Venus

N. KLEEORIN, I. ROGACHEVSKII and A. EVIATAR

\section{History}

The Cosmic Dynamo: From $t=-\infty$ to Cowling's Theorem. A Review on History F. KRAUSE 